\title{
Powder Treatment for Increased Thickness of Iron Coatings Produced by the Powder Aerosol Deposition Method and Formation of Iron-Alumina Multilayer Structures
}

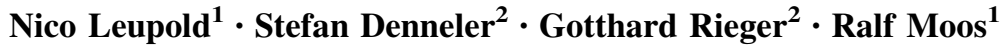

Submitted: 9 April 2020/in revised form: 23 July 2020/Accepted: 14 September 2020/Published online: 22 October 2020

(C) The Author(s) 2020

\begin{abstract}
The powder aerosol deposition (PAD) method is a well-known process to fabricate dense layers at room temperature directly from the powder. It is particularly suitable for the deposition of ceramic materials. Compared to these, the use of metal powders (here iron), which are significantly more ductile and have a higher density than typical ceramic powders, has not yet been investigated in detail for PAD. In the first step of this work, the iron powder is characterized by scanning electron microscopy and x-ray diffraction. In order to improve the deposition behavior, the influence of heat treatment on the crystallite and the particle size of the iron powder is investigated. It is shown that the crystallite size of iron powders is reduced down to a nanocrystalline size during deposition. The magnetic properties of the iron powder as well as the layers are investigated by means of coercive field development. Although the initial coercivity raises after deposition, potential applications for flux guiding in microelectronic sensors and devices are feasible. In the second step, thin metal layers (iron) and ceramics (aluminum oxide) are
\end{abstract}

This article is part of a special topical focus in the Journal of Thermal Spray Technology on Aerosol Deposition and Kinetic Spray Processes. This issue was organized by Dr. Kentaro Shinoda, National Institute of Advanced Industrial Science and Technology (AIST); Dr. Frank Gaertner, Helmut-Schmidt University; Prof. Changhee Lee, Hanyang University; Prof. Ali Dolatabadi, Concordia University; and Dr. Scooter Johnson, Naval Research Laboratory.

Ralf Moos

functional.materials@uni-bayreuth.de

1 Department of Functional Materials, University of Bayreuth, 95440 Bayreuth, Germany

2 Siemens AG, Corporate Technology, 81739 Munich, Germany deposited alternatingly to produce iron-alumina multilayer structures.

Keywords aerosol deposition method (ADM) - crystallite size - magnetic coercivity $\cdot$ metal deposition $\cdot$ microstrain . room temperature impact consolidation (RTIC) · vacuum kinetic spraying (VKS)

\section{Introduction}

The powder aerosol deposition (PAD) method (or only aerosol deposition method, ADM (Ref 1)) is an intensively studied method to produce dense ceramic layers directly from the powder at room temperature. In short, in the PAD process, the powders are converted into an aerosol with the help of a carrier gas flow and fed into the deposition chamber via a nozzle. The deposition chamber is evacuated to a few mbar by means of a pump, which accelerates the aerosol to several hundred meters per second due to the pressure difference. When the particles hit the substrate in the deposition chamber at high speed, they break up and form the nanocrystalline layer. Subsequent particles deform, crush and compress the layer further (hammering effect) (Ref 2). Since the film forms at room temperature, the whole deposition mechanism is called room temperature impact consolidation (RTIC) (Ref 3). More details can be found in the reviews of Akedo et al. (Ref 3 ) and Hanft et al. (Ref 4). Various functional materials such as semiconductors (Ref 5,6), insulators (Ref 7,8), solid-state ion conductors (Ref 9), superconductors (Ref 10), thermoelectric (Ref 11,12) and magnetic materials (Ref 13, 14), to just give a few examples, were successfully deposited and their properties investigated. An overview on investigated materials is provided by the reviews from Schubert 
et al. (Ref 15) and on first commercial applications by Akedo (Ref 16). However, these overview articles review the deposition of ceramics.

The deposition of metallic powders, on the other hand, is by far less thoroughly explored. First, investigations on the PAD of iron were carried out as co-deposition together with ceramic spinels like $(\mathrm{NiZnCu}) \mathrm{Fe}_{2} \mathrm{O}_{4}$ or $(\mathrm{NiZn}) \mathrm{Fe}_{2} \mathrm{O}_{4}$. The magnetic permeability of the layer and the associated microwave absorption could be increased to reduce noise in $\mathrm{GHz}$ applications (Ref 17, 18). In this context, also $\mathrm{Fe} /$ $(\mathrm{NiZnCu}) \mathrm{Fe}_{2} \mathrm{O}_{4}$ stacked films were presented, where iron and the ferrite were deposited alternately (Ref 19). Kim et al. showed, using silver powder, that due to the low hardness of the particles, it is difficult to form an anchor layer on smooth substrates such as glass, and therefore, the layers are easily peeled off. However, firmly adhering silver layers could be achieved by mechanical interlocking with rough alumina substrates (Ref 20). The influence of the size of the nozzle orifice and the gas flow rate on the electrical conductivity of Ag-PAD layers was investigated by Cho et al., whereby the electrical conductivity increased with decreasing nozzle orifice size and increasing gas flow rate (Ref 21). They attributed this to a stronger plastic deformation of the particles and thus a better densification of the layer. The same improvement in coating adhesion using rougher substrates is found in the case of copper as a coating material. It was also explained by the mechanical interlocking of the copper particles with the substrate (Ref 22). The influence of the copper particle size on coating formation was investigated in a subsequent study (Ref 23). While layers of high quality could be produced with a particle size of $2 \mu \mathrm{m}$, the quality of layers with particles larger than $5 \mu \mathrm{m}$ decreased drastically. Here, too, the plastic deformation of the particles was primarily considered responsible for the layer formation.

In the first part of this work, the influence of crystallite size on the deposition behavior of iron powder by PAD is investigated. To improve the layer formation, the powder was heat-treated without affecting the particle size distribution strongly. The crystallite size and the microstrain of powders and layers are determined by XRD and discussed in the context of ceramic materials. Although the coercive field increases after deposition, potential applications for flux guiding in microelectronic sensors and devices are feasible. Finally, the fabrication of iron-alumina multilayer structures using the PAD method is shown.

\section{Experimental}

\section{Materials}

A commercially available iron powder (Alfa Aesar) with a specified mean particle size of $2 \mu \mathrm{m}$ and a purity of $98 \%$ was used as a starting material. The main impurities consisted of carbon, oxygen and nitrogen as listed in the supplier's data sheet. The iron was in its $\alpha$-phase. Alumina powder for preparation of insulating layers with a mean particle size of $700 \mathrm{~nm}$ was purchased from Showa Denko. As substrate for deposition, either alumina (Rubalit ${ }^{\circledR} 710$, CeramTec) or copper (CW024A-R240, Sofia Med) was used.

\section{Iron Powder Heat Treatment}

In order to vary crystallite size and thus observe the effect on the deposition behavior of the raw and heat-treated powders, the as-received powder was filled into a quartz glass crucible and heat-treated at 250,350 and $450{ }^{\circ} \mathrm{C}$ in an alumina tube furnace for $7 \mathrm{~h}$. Heating and cooling rate was set to $5{ }^{\circ} \mathrm{C} / \mathrm{min}$. The furnace was flushed with argon gas to avoid oxidation of the powder. Since the powder would oxidize immediately, powder removal from the furnace was done at room temperature, followed by storage in a nitrogen-flushed desiccator. After heat treatment, the powder was sieved (90 $\mu \mathrm{m}$ mesh size) to break up large agglomerates.

\section{Powder Aerosol Deposition Conditions}

For film deposition, a custom-made PAD apparatus comparable to the one previously reported in (Ref 24) and a nozzle with an outlet slit orifice of $10 \mathrm{~mm}$ by $0.5 \mathrm{~mm}$ were used. For iron deposition, the substrate was moved horizontally at a speed of $1 \mathrm{~mm} / \mathrm{s}$ and the distance to the nozzle was $5 \mathrm{~mm}$. Argon and helium were used as processing gas with a flow rate of 2-6 and 2-9 L/min, respectively. Alumina was deposited at a substrate-to-nozzle distance of $2 \mathrm{~mm}$ and a substrate velocity of $10 \mathrm{~mm} / \mathrm{s}$ with an oxygen flow rate of $4 \mathrm{~L} / \mathrm{min}$.

\section{Characterization of the Powder and Coating}

The structural and phase characterization of the perovskite powders was carried out by reflection mode XRD using a Bruker "D8 Discover A25" with $\mathrm{Cu}-\mathrm{K}_{\alpha \mathrm{I}}$ radiation $(\lambda=0.15406 \mathrm{~nm})$, whereby the $\mathrm{K}_{\alpha \mathrm{II}}$-rays were removed by a Ge- $\mathrm{K}_{\alpha \mathrm{I}}$ monochromator. The device was operated at $40 \mathrm{kV}$ and $40 \mathrm{~mA}$. The diffraction patterns were recorded in the $2 \Theta$-range from $40^{\circ}$ to $105^{\circ}$ with a $2 \Theta$-step size of $0.016^{\circ}$. The diffraction patterns from as-received powder, powder heat-treated at $250{ }^{\circ} \mathrm{C}$ and for both PAD films were smoothed with an FFT filter (fast Fourier transformation).

The powder and film morphology was characterized by SEM using a Zeiss Leo 1530 instrument with an accelerating voltage of $3.0 \mathrm{kV}$. For energy-dispersive $\mathrm{x}$-ray spectroscopy (EDX), an accelerating voltage of $20 \mathrm{kV}$ and 
an UltraDry-EDX-Detector (Thermo Fisher Scientific NS7) were used.

The particle size distribution was measured using a Malvern Panalytical Mastersizer 2000. With a Jenoptik profilometer "Waveline W20", the surface roughness of substrates and resulting coatings was determined according to ISO 4287.

The magnetic properties of powder and multilayer were measured with an earth-field-shielded solenoid using a Förster magnetometer (Institut Dr. Förster, Reutlingen, Germany). This system accurately determines the coercive field strength of magnetic materials in an open magnetic circuit. The sample is placed into the solenoid and magnetized up to saturation. The coercive field strength $H_{\mathrm{cJ}}$ is measured by demagnetization of the sample until zero polarization is reached.

\section{Results and Discussion}

Figure 1(a) and (b) shows two SEM images of the as-received iron powder. The primary particles have a spherical shape and are loosely bound to larger agglomerates. The tendency toward agglomeration of the iron powder is low. The spherical primary particles again show a fine substructure leading to the conclusion that the particles themselves are nanocrystalline. To confirm the observation, the powder was investigated by XRD. Rietveld refinement of the resulting pattern discloses a very small crystallite size of $23 \mathrm{~nm}$ with a considerable microstrain of $0.42 \%$. The median particle size $\left(d_{50}=2.1 \mu \mathrm{m}\right)$ is suitable for PAD as shown in the literature (Ref 19, 23). The data also confirm the phase purity and the absence of larger amounts of impurities.

The coatings obtained from the as-received iron powder, i.e., with no previous heat treatment, are thin (below $400 \mathrm{~nm}$ ) and firmly adhering, both if deposited on $\mathrm{Al}_{2} \mathrm{O}_{3}$ and on copper over a large range of gas flow rates (i.e., helium or argon, 2-6 L/min). Figure 1(c) shows an exemplary cross-sectional SEM image of an iron PAD layer, obtained using an argon flow rate of $3 \mathrm{~L} / \mathrm{min}$, on top of an alumina substrate. As can be seen in the image, especially the pits on the substrate are filled up, while the layer on the tips of the rough substrate is very thin. Nevertheless, the substrate is completely covered with the iron PAD layer. The layer thicknesses are in the range of $400 \mathrm{~nm}$ in the pits and below $100 \mathrm{~nm}$ on the tips. The filling of the pits is also confirmed by measuring the surface roughness. While the substrate has a centerline average roughness of $R_{\mathrm{a}}=0.11 \mu \mathrm{m}$, the roughness is almost halved to $R_{\mathrm{a}}=0.06 \mu \mathrm{m}$ by the iron layer. This thin metallization layer forms after only a few scans, but does not grow noticeably afterward. One reason for this could be a high hardness due to the small crystallite size $(23 \mathrm{~nm})$ (Ref $25,26)$ and the microstrain of the iron particles. Both hinder the movement of dislocations and increase hardness. The high hardness of the particles could also lead to a persistent abrasion of the forming layer and thus prevent additional layer growth.

In order to increase the achievable layer thicknesses, the powders were heat-treated at temperatures of 250, 350 and $450{ }^{\circ} \mathrm{C}$. The aim was to increase the crystallite size and reduce microstrain without increasing the particle size significantly, as the particle size is in a range suitable for PAD. The result of the particle size distribution measurements of untreated powder and after the respective heat treatment is shown in Fig. 2(a). At a heat treatment temperature of 250 and $350{ }^{\circ} \mathrm{C}$, the particle size distribution changes only slightly, while at $450{ }^{\circ} \mathrm{C}$, the distribution shifts toward larger particle sizes. This is also evident when comparing the $d_{50}$ values (Table 1 ). They hardly change from untreated to 250 and $350{ }^{\circ} \mathrm{C}$ with $2.1,2.0$ and $2.3 \mu \mathrm{m}$, respectively. In contrast, the $d_{50}$ at $450{ }^{\circ} \mathrm{C}$ is 1.5 times larger with $3.5 \mu \mathrm{m}$. Overall, the change is still acceptable, as there is no strong sintering of the complete powder.

Figure 2(b) shows the influence of the heat treatment temperature on the reflection width in the $\mathrm{x}$-ray diffraction pattern. Due to the better representability, only the

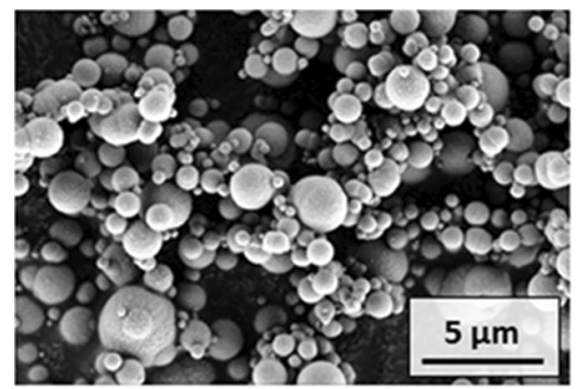

(a)

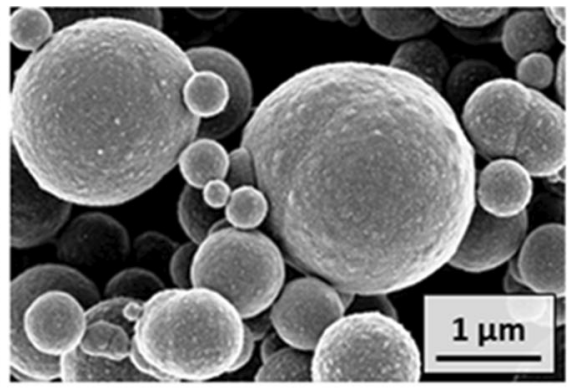

(b)

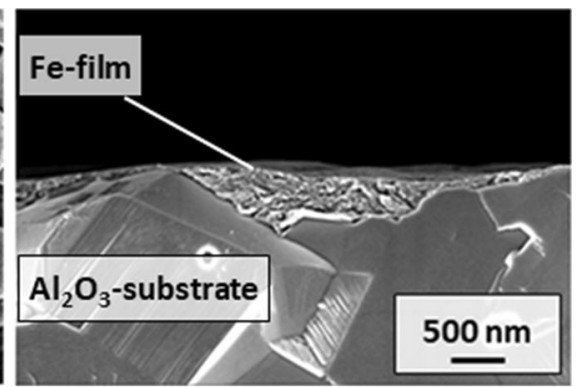

(c)

Fig. 1 (a), (b) SEM images of as-received iron powder with two different magnifications. (c) Cross-sectional SEM image of an iron PAD layer on top of an alumina substrate 
Fig. 2 (a) Particle size distribution of as-received and heat-treated iron powder $(250$, 350 and $450{ }^{\circ} \mathrm{C}$ ). (b) Influence of heat treatment temperature on the reflection width in the XRD pattern of iron powder shown exemplarily for the reflection from the (011) plane

Table 1 Particle size, crystallite size and microstrain for as-received and heat-treated iron powder
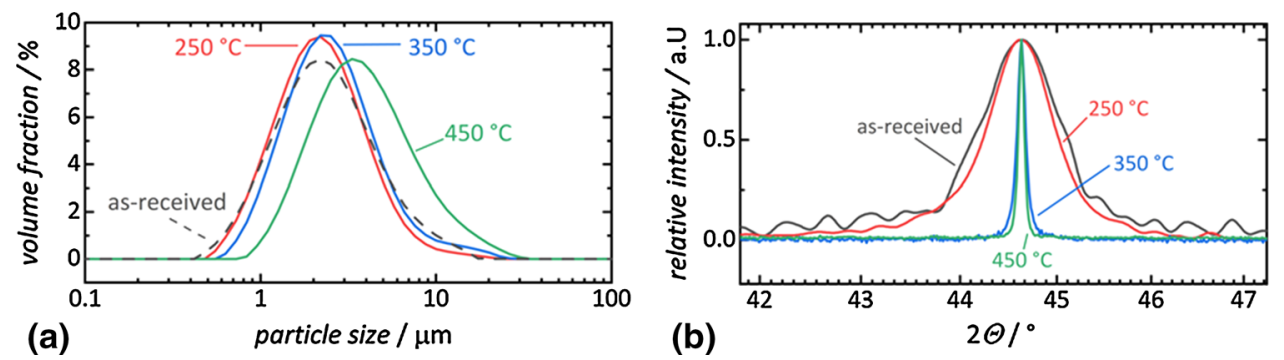

\begin{tabular}{lccccc}
\hline Heat treatment temperature & $d_{10} / \mu \mathrm{m}$ & $d_{50} / \mu \mathrm{m}$ & $d_{90} / \mu \mathrm{m}$ & Crystallite size/nm & Microstrain/\% \\
\hline As-received & 1.0 & 2.1 & 5.2 & 23 & 0.42 \\
$250{ }^{\circ} \mathrm{C}$ & 1.0 & 2.0 & 4.4 & 23 & 0.32 \\
$350{ }^{\circ} \mathrm{C}$ & 1.1 & 2.3 & 5.2 & 170 & 0.03 \\
$450{ }^{\circ} \mathrm{C}$ & 1.6 & 3.5 & 8.7 & 250 & 0.01 \\
\hline
\end{tabular}

reflection of the (011) plane is shown and all measurements are normalized to this reflection. At a heat treatment temperature of $250{ }^{\circ} \mathrm{C}$, there is no change in the reflection width compared to the untreated powder, whereas the reflection is significantly narrower after a heat treatment at $350{ }^{\circ} \mathrm{C}$. The reflection of the powder after applying $450{ }^{\circ} \mathrm{C}$ is even thinner. With the help of Rietveld refinement, both crystallite size and microstrain can be determined from the reflection broadening over the entire diffraction pattern. The result is also shown in Table 1. As can be seen there and can be concluded from the fact that the reflection width is not decreasing, the crystallite size $(23 \mathrm{~nm})$ does not change during the heat treatment at $250{ }^{\circ} \mathrm{C}$. Only the microstrain is slightly reduced from 0.42 to $0.32 \%$. With a heat treatment at $350{ }^{\circ} \mathrm{C}$, however, the crystallite size increases to $170 \mathrm{~nm}$ and the microstrain decreases significantly to $0.03 \%$. The further increased heat treatment temperature of $450{ }^{\circ} \mathrm{C}$ leads to a further increase in the crystallite size to $250 \mathrm{~nm}$ and an almost complete disappearance of the microstrain. It should be noted here that for crystallite sizes $>150 \mathrm{~nm}$, the absolute values are inaccurate, but the trend remains the same. Thus, by a mild heat treatment of metallic powders, just as with ceramic powders (Ref 27), the crystallite size is increased and the microstrain reduced, while at the same time, the particle size distribution is not changed.

With the heat-treated powders, new experiments were carried out to produce PAD layers. As expected, powder heat-treated at $250{ }^{\circ} \mathrm{C}$ behaves similar to as-received powder. It was, therefore, possible to deposit thin layers with a variety of parameters on $\mathrm{Al}_{2} \mathrm{O}_{3}$ and copper, but it also seems hard to realize thick layers. Thus, in the next step, the deposition of iron films from powder heat-treated at $350{ }^{\circ} \mathrm{C}$ was investigated. Utilizing an argon flow rate of $3 \mathrm{~L} / \mathrm{min}$, a $1-\mu \mathrm{m}$-thick film on copper can be deposited.
Figure 3 shows SEM images of an iron PAD film obtained using powder heat-treated at $350{ }^{\circ} \mathrm{C}$ and an increased argon flow rate of $6 \mathrm{~L} / \mathrm{min}$ with (a) low magnification and (b) high magnification. With these parameters, a layer thickness of $2 \mu \mathrm{m}$ on copper can be achieved. As typical for PAD layers, the iron layer shows a pore-free interface to the substrate and is dense. By changing the carrier gas to helium, iron layers up to a thickness of $25 \mu \mathrm{m}$ can be produced on copper with a flow rate of $6 \mathrm{~L} / \mathrm{min}$.

In order to better understand the layer formation of PAD with metal powder, a $25-\mu \mathrm{m}$-thick PAD layer was investigated in detail by XRD. The corresponding diffraction pattern is shown in Fig. 4(a). The reflections of iron are clearly visible, i.e., the iron retains its $\alpha$-phase and is not converted into austenite by the impact during deposition. The reflections marked with an asterisk can be assigned to the copper substrate. No signs of impurities, such as iron oxide, appear in the diffraction patterns.

Figure 4(b) shows a section of the diffraction pattern of as-received powder, heat-treated powder at $350{ }^{\circ} \mathrm{C}$ and the PAD layer made from it to compare the reflection width of the (011) reflection. It can be seen that the reflection width has decreased significantly after heat treatment but increases again in the layer and comes closer to the width of the as-received powder. The Rietveld refinement on the film results in values of $32 \mathrm{~nm}$ and $0.30 \%$ for the crystallite size and microstrain, respectively. Thus, the crystallite size after deposition is only about $1 / 5$ of the original one. The microstrain of $0.30 \%$ matches well with the microstrain of $0.34 \%$ reported in the literature for PAD of copper particles with $2 \mu \mathrm{m}$ diameter $(\operatorname{Ref} 23)$.

In comparison, with powder that was heat-treated at $450{ }^{\circ} \mathrm{C}$ only very thin layers (below $300 \mathrm{~nm}$ ) could be produced, even with a helium flow rate of $6 \mathrm{~L} / \mathrm{min}$, which worked well for powder heat-treated at $350{ }^{\circ} \mathrm{C}$. At an 

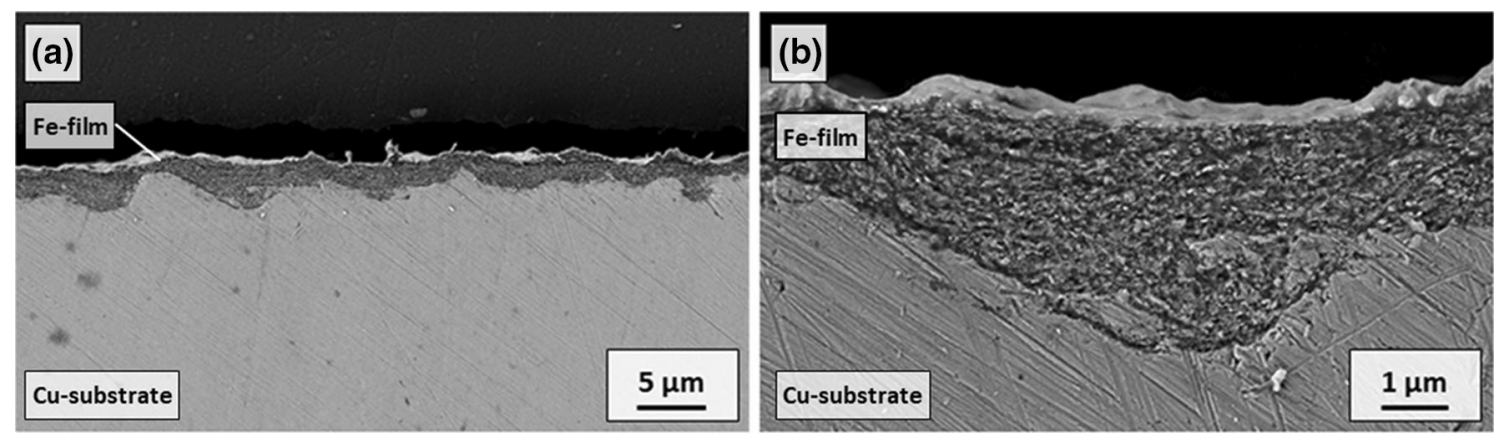

Fig. 3 SEM images of an iron PAD film obtained using powder heat-treated at $350{ }^{\circ} \mathrm{C}$ and an argon flow rate of $6 \mathrm{~L} / \mathrm{min}$ with (a) low magnification and (b) high magnification

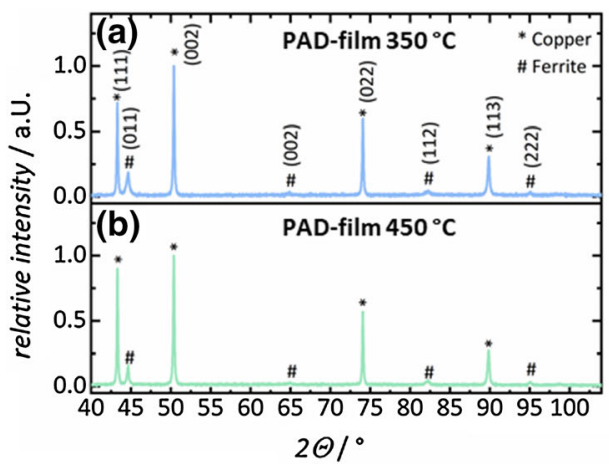

Fig. 4 (a) XRD pattern of an iron PAD film made from powder heattreated at $350{ }^{\circ} \mathrm{C}$ on top of a copper substrate showing the phase purity of the iron layer. (b) Comparison of the reflection widths from the (011) plane in the XRD pattern of as-received powder, powder heat-treated at $350{ }^{\circ} \mathrm{C}$ and the obtained PAD film. (c) XRD pattern of

increased helium flow rate of $9 \mathrm{~L} / \mathrm{min}$, coatings with a film thickness of up to $9 \mu \mathrm{m}$ can be produced. We attribute this on one hand to the low powder ejection rate at 3-6 L/min due to the larger diameter of the particles and their corresponding larger mass. On the other hand, the particle velocity changes when increasing the gas flow rate. The thickness of films made with powder heat-treated at $450{ }^{\circ} \mathrm{C}$ was limited to about $9 \mu \mathrm{m}$ because at higher thickness, films would delaminate partially.

The XRD patterns, depicted in Fig. 4(c), show a similar result like the powder that was heat-treated at $350{ }^{\circ} \mathrm{C}$. Again, no reflections of impurities are detectable and the iron PAD layer consists of only iron in the ferrite phase. There is a small difference in the texture of the rolled copper sheet, which, however, is within the typical materials variations. Here again, the reflections in the diffraction pattern of the layer are widened compared to the powder, as illustrated in Fig. 4(d), also using the reflection of the (011) plane as an example. The crystallite size decreases from $250 \mathrm{~nm}$ in the powder by about $1 / 5$ to $57 \mathrm{~nm}$ in the layer, while the microstrain increases from 0.01 to $0.17 \%$.

In the literature, the necessity of a reduction of the crystallite size with simultaneous introduction of

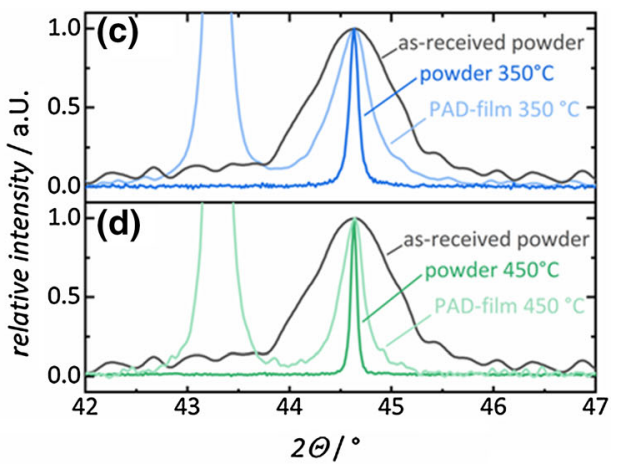

an iron PAD film made from powder heat-treated at $450{ }^{\circ} \mathrm{C}$ on top of a copper substrate showing the phase purity of the iron layer. (d) Comparison of the reflection widths from the (011) plane in the XRD pattern of as-received powder, powder heat-treated at $450{ }^{\circ} \mathrm{C}$ and the obtained PAD film

microstrain for a successful layer formation has been described on the basis of ceramic $\mathrm{CeO}_{2}$ (Ref 27). There, a reduction of the crystallite size to $1 / 3$ is reported as insufficient for successful deposition, whereas a reduction to $1 / 15$ leads to film formation. The reduction of the crystallite size to $1 / 5$ for iron powder is therefore at the lower limit of the ratio defined there. The introduced microstrain of $0.30 \%$ at $350{ }^{\circ} \mathrm{C}$, respectively, of $0.17 \%$ at $450{ }^{\circ} \mathrm{C}$ is lower compared to the introduced microstrain of $0.5 \%$ in the $\mathrm{CeO}_{2}-\mathrm{PAD}$ layers. Both crystallite size reduction and microstrain indicate that for successful deposition of thick iron films, it is necessary to have a crystallite size that is large enough and that is reduced during the deposition. It also suggests that a certain amount of plastic deformation of the impacting particles occurs as was already found in the literature (Ref 21-23). The very fine structure of the iron coatings as shown in the SEM image in Fig. 3(b) suggests that the iron particles break up during deposition, comparable to the deposition mechanism of ceramic particles.

The deposition of metals via PAD is closely related to another advanced spray coating process called cold spray (CS). CS is mainly used to deposit metal coatings. The 


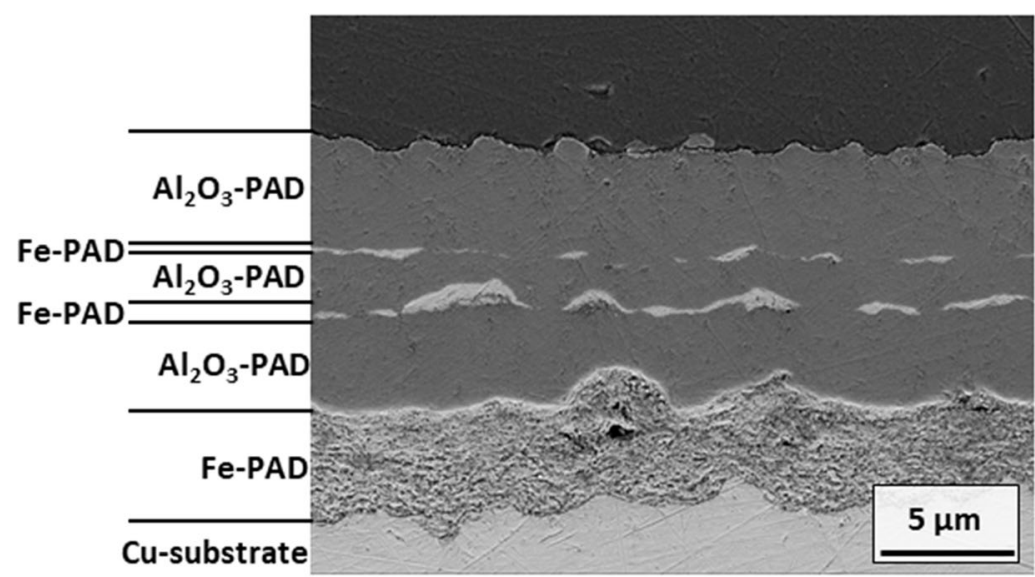

(a)

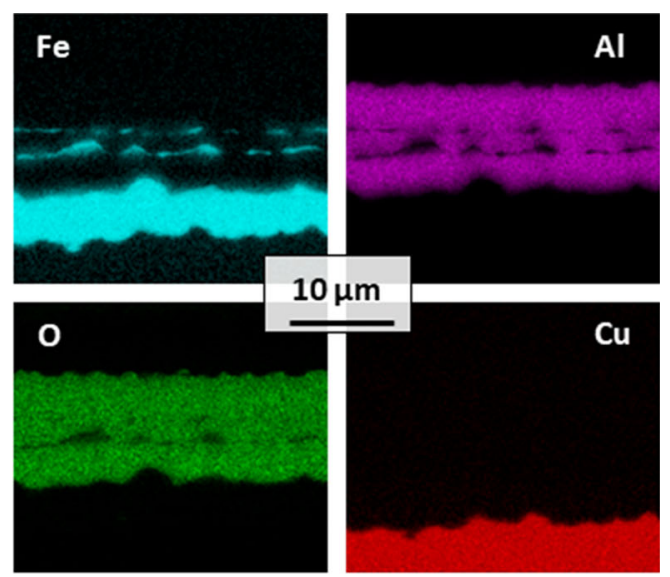

(b)

Fig. 5 (a) SEM image of a polished section of an iron-alumina multilayer structure on top of a copper substrate. (b) Distribution of Fe, O, Al and $\mathrm{Cu}$ obtained via EDX

main differences to PAD are: larger particle size between 5 and $50 \mu \mathrm{m}$, usage of carrier gas temperature up to $700{ }^{\circ} \mathrm{C}$, larger carrier gas flow between 1 and $3 \mathrm{~m}^{3} / \mathrm{min}$, higher carrier gas pressure of 1-3 $\mathrm{MPa}$ and ambient conditions in the deposition chamber (Ref 28). In contrast to the crystallite size reduction by fracturing of the (usually ceramic) particles in PAD, the reduced crystallite size in the coldsprayed metal coatings is often attributed to dynamic recrystallization processes (Ref 29,30 ). Upon impact of a particle onto the substrate or the readily formed film, the particle is plastically deformed with high strain rates and the temperature is increased at the interface (Ref 31). Under these circumstances, new nanosized crystallites can be formed under deformation (Ref 32, 33). Further investigations are required to clarify the exact deposition mechanism of metals via PAD.

In order to investigate the influence of the deposition on the magnetic properties of the iron, measurements of the in-plane coercive field $H_{\mathrm{cJ}}$ were conducted. The as-received powders and heat-treated powders show a coercivity in the range from 0.15 to $0.20 \mathrm{kA} / \mathrm{m}$. This is in an expected range for iron with a mean particle size of a few micrometers (Ref 34) and can be classified as a soft magnetic material. After deposition, the coercive field of the film increases to $6.1 \mathrm{kA} / \mathrm{m}$ for powder heat-treated at $350{ }^{\circ} \mathrm{C}$ and to $4.0 \mathrm{kA} / \mathrm{m}$ for powder heat-treated at $450{ }^{\circ} \mathrm{C}$. Thus, the coercivity of the films now indicates a semi-hard magnetic behavior. Possible reasons for the increase could be a combination of crystal size, introduced film stresses during deposition and micropores and microcracks altogether limiting the movement of domain walls even at small crystallite sizes (Ref 35 ). An increase in coercive field in the PAD film compared to the powder is also reported in the literature for $\mathrm{Sm}_{2} \mathrm{Fe}_{17} \mathrm{~N}_{\mathrm{x}}$ (Ref 36, 37) and for $\mathrm{Fe} /(\mathrm{NiZnCu}) \mathrm{Fe}_{2} \mathrm{O}_{4}$ composite films (Ref 17). For ceramic $\mathrm{NiZnCu}$, the coercive field also increased after deposition, while the crystallite size in the film was about $20 \mathrm{~nm}$. Since annealing of the film increased the crystallite size of the film to the crystallite size of the powder (60$100 \mathrm{~nm}$ ) and released the stresses, while the coercive field remained high, it was concluded that besides the wellknown grain-size dependence in nanocrystalline ferromagnets (Ref 38), also film defects have a big impact on the coercive field of magnetic ceramic PAD films (Ref 39). This is a common feature originating from additional domain wall pinning sites found in films produced by rather different methods (e.g., (Ref 40)).

Finally, experiments were carried out to cover the iron layers with alumina and, based on this, to build the multilayer structure. With the help of multilayer structures, several functional layers can be superimposed on the same area in order to make better use of the available space. By separating the individual layers, however, the functional film can also achieve a better effect in some applications like magnetic shielding or reduced losses in inductors and transformers. In addition, a gas-tight and electrically insulating sealing layer protects the underlying metal from corrosion. The results of the experiments show that the $\mathrm{Fe}$ PAD layers can be covered with dense and solid $\mathrm{Al}_{2} \mathrm{O}_{3}$ layers by using the same parameters (nitrogen or oxygen, flow rate 4-6 L/min), as they are also used for direct coating of steel substrates.

Figure 5(a) shows an SEM image of a polished section of an iron-alumina multilayer structure on a copper substrate. First, a 3.5- $\mu$ m-thick Fe-PAD layer was applied to the copper substrate. Powder with a heat treatment temperature of $450{ }^{\circ} \mathrm{C}$ and a helium flow rate of $9 \mathrm{~L} / \mathrm{min}$ was used. As in the previous figures, the first iron layer is compact and shows good adhesion to the substrate. A $600 \mathrm{~nm}$ large pore is visible in the middle. The overlying 
$\mathrm{Al}_{2} \mathrm{O}_{3}$ layer is dense, and the pore-free interface suggests a good bonding to the underlying Fe-PAD layer. The next Fe-PAD layer is much thinner, although the fabrication parameters are the same as for the first iron layer. This indicates a significant influence of the substrate hardness on the layer growth. Afterward, another $\mathrm{Al}_{2} \mathrm{O}_{3}$ layer, another thin iron layer and finally a third $\mathrm{Al}_{2} \mathrm{O}_{3}$ covering layer were applied.

To confirm the visual impression of the layer sequence, a mapping of the elements was carried out at the same position using EDX. The distribution of the elements is shown in Fig. 5(b). The three iron layers are clearly visible in the mapping of the iron, and the two thin layers are also well resolved. In the aluminum mapping, the iron layers are also clearly distinguished by the absence of the Al signals. This means that there are no alumina particles, respectively, fragments mixed into the iron layer during the coating process. The iron layer also stands out as a negative in the mapping of the oxygen, but not so clearly. A slight oxidation of the surface after polishing the sample might be the reason for that. Nevertheless, the results indicate that iron is present as elemental iron. Finally, the mapping of copper is shown for completeness. All these results show the successful fabrication of an iron-alumina multilayer structure by using PAD.

\section{Conclusion}

In summary, the influence of the crystallite size on the deposition behavior of iron powder was investigated with the aim of producing iron-alumina multilayer structures. We show that iron powder with too small crystallite size can only be deposited as very thin metallization layers. By heat treatment at low temperatures of $350-450{ }^{\circ} \mathrm{C}$, a growth of the crystallites is initiated without affecting the particle size significantly. Heat-treated powder was then used to produce PAD layers with a layer thickness of up to $25 \mu \mathrm{m}$. As with ceramic powders, the crystallite size is reduced during deposition and microstrain is introduced into the film. However, the reduction of the crystallite size from 30 to $60 \mathrm{~nm}$ and the introduced microstrain of $0.17-0.30 \%$ is lower than for typical ceramic powders. This suggests a higher degree of plastic deformation in metal powders during film consolidation compared to ceramics. The coercivity, which determines the soft magnetic behavior, was found to increase from $0.2 \mathrm{kA} / \mathrm{m}$ in the powders up to $6.1 \mathrm{kA} / \mathrm{m}$ in films. Finally, we successfully fabricated ironalumina multilayer structures using PAD.

Acknowledgments The authors acknowledge the Department of Metal and Alloys (Prof. Uwe Glatzel) for the possibility to conduct XRD measurements, Angelika Mergner and the Keylab Electron and
Optical Microscopy of the Bavarian Polymer Institute (BPI) for SEM images and Gabriele Jena from the Department for Applied Mechanics und Fluid Dynamics for particle size distribution measurements (all University of Bayreuth).

Open Access This article is licensed under a Creative Commons Attribution 4.0 International License, which permits use, sharing, adaptation, distribution and reproduction in any medium or format, as long as you give appropriate credit to the original author(s) and the source, provide a link to the Creative Commons licence, and indicate if changes were made. The images or other third party material in this article are included in the article's Creative Commons licence, unless indicated otherwise in a credit line to the material. If material is not included in the article's Creative Commons licence and your intended use is not permitted by statutory regulation or exceeds the permitted use, you will need to obtain permission directly from the copyright holder. To view a copy of this licence, visit http://creativecommons. org/licenses/by/4.0/.

Funding Open Access funding enabled and organized by Projekt DEAL.

\section{References}

1. J. Akedo, Aerosol Deposition Method for Fabrication of Nano Crystal Ceramic Layer, Mater. Sci. Forum, 2004, 449-452, p 4348

2. D.-W. Lee, H.-J. Kim, Y.-H. Kim, Y.-H. Yun, and S.-M. Nam, Growth Process of $\alpha-\mathrm{Al}_{2} \mathrm{O}_{3}$ Ceramic Films on Metal Substrates Fabricated at Room Temperature by Aerosol Deposition, J. Am. Ceram. Soc., 2011, 94(9), p 3131-3138

3. J. Akedo, Room Temperature Impact Consolidation (RTIC) of Fine Ceramic Powder by Aerosol Deposition Method and Applications to Microdevices, J. Therm. Spray Technol., 2008, 17(2), p 181-198

4. D. Hanft, J. Exner, M. Schubert, T. Stöcker, P. Fuierer, and R. Moos, An Overview of the Aerosol Deposition Method: Process Fundamentals and New Trends in Materials Applications, $J$. Ceram. Sci. Technol., 2015, 6(3), p 147-182

5. J.-J. Park, J.-G. Lee, D.-Y. Kim, J.-H. Lee, J.H. Yun, J. Gwak, Y.J. Eo, A. Cho, M.T. Swihart, S.S. Al-Deyab, S. Ahn, D. Kim, and S.S. Yoon, Rapid supersonic spraying of $\mathrm{Cu}(\mathrm{In}, \mathrm{Ga})(\mathrm{S}, \mathrm{Se}) 2$ nanoparticles to fabricate a solar cell with $5.49 \%$ conversion efficiency, Acta Mater., 2017, 123, p 44-54

6. F. Panzer, D. Hanft, T.P. Gujar, F.-J. Kahle, M. Thelakkat, A. Köhler, and R. Moos, Compact Layers of Hybrid Halide Perovskites Fabricated via the Aerosol Deposition Process-Uncoupling Material Synthesis and Layer Formation, Materials, 2016, 9(4), p 277

7. N. Leupold, M. Schubert, J. Kita, and R. Moos, Influence of High Temperature Annealing on the Dielectric Properties of Alumina Films Prepared by the Aerosol Deposition Method, Funct. Mater. Lett., 2018, 11(2), p 1850022

8. M. Schubert, N. Leupold, J. Exner, J. Kita, and R. Moos, HighTemperature Electrical Insulation Behavior of Alumina Films Prepared at Room Temperature by Aerosol Deposition and Influence of Annealing Process and Powder Impurities, J. Therm. Spray Technol., 2018, 27(5), p 870-879

9. J.-J. Choi, J. Ryu, B.-D. Hahn, C.-W. Ahn, J.-W. Kim, W.-H. Yoon, and D.-S. Park, Low Temperature Preparation and Characterization of Solid Oxide Fuel Cells on FeCr-Based Alloy Support by Aerosol Deposition, Int. J. Hydrog. Energy, 2014, 39, p $12878-12883$ 
10. S. Kauffmann-Weiss, W. Hässler, E. Guenther, J. Scheiter, S. Denneler, P. Glosse, T. Berthold, M. Oomen, T. Arndt, T. Stöcker, D. Hanft, R. Moos, M. Weiss, F. Weis, and B. Holzapfel, Superconducting Properties of Thick Films on Hastelloy Prepared by the Aerosol Deposition Method With Ex Situ $\mathrm{MgB}_{2}$ Powder, IEEE Trans. Appl. Supercond., 2017, 27(4), p 6200904

11. M.H. Kwak, S.B. Kang, J.H. Kim, J. Lee, S.-M. Lee, W.-J. Kim, and S.E. Moon, Aerosol Deposition of Thermoelectric p-Type $\mathrm{Bi}_{0.5} \mathrm{Sb}_{1.5} \mathrm{Te}_{3}$ and n-Type $\mathrm{Bi}_{2} \mathrm{Te}_{2.7} \mathrm{Se}_{0.3}$ Thick Films, J. Ceram. Process. Res., 2017, 18(10), p 731-734

12. T. Stöcker, J. Exner, M. Schubert, M. Streibl, and R. Moos, Influence of Oxygen Partial Pressure During Processing on the Thermoelectric Properties of Aerosol-Deposited $\mathrm{CuFeO}_{2}$, Materials, 2016, 9(4), p 227

13. T. Maki, S. Sugimoto, T. Kagotani, K. Inomata, and J. Akedo, Microstructure and magnetic properties of aerosol-deposited SmFe-N thick films, Electr. Eng. Jpn., 2007, 158(1), p 8-13

14. S.D. Johnson, C.M. Gonzalez, V. Anderson, Z. Robinson, H.S. Newman, S. Shin, and S.B. Qadri, Magnetic and Structural Properties of Sintered Bulk Pucks and Aerosol Deposited Films of Ti-Doped Barium Hexaferrite for Microwave Absorption Applications, J. Appl. Phys., 2017, 122(2), p 24901

15. M. Schubert, D. Hanft, T. Nazarenus, J. Exner, M. Schubert, P. Nieke, P. Glosse, N. Leupold, J. Kita, and R. Moos, Powder Aerosol Deposition Method: Novel Applications in the Field of Sensing and Energy Technology, Funct. Mater. Lett., 2019, 12(05), p 1930005

16. J. Akedo, Room Temperature Impact Consolidation and Application to Ceramic Coatings: Aerosol Deposition Method, $J$. Ceram. Soc. Jpn., 2020, 128(3), p 101-116

17. S. Sugimoto, K. Haga, M. Nakata, T. Kagotani, K. Inomata, and J. Akedo, Magnetic Properties of $\mathrm{Fe} /(\mathrm{NiZnCu}) \mathrm{Fe}_{2} \mathrm{O}_{4}$ Composite Films Prepared by Aerosol Deposition Method, IEEE Trans. Magn., 2005, 41(10), p 3460-3462

18. Y. Kato, S. Sugimoto, and J. Akedo, Magnetic Properties and Electromagnetic Wave Suppression Properties of Fe-Ferrite Films Prepared by Aerosol Deposition Method, Jpn. J. Appl. Phys., 2008, 47(4), p 2127-2131

19. S. Sugimoto, V. Chan, M. Noguchi, N. Tezuka, K. Inomata, and J. Akedo, Preparation of Fe/Ni-Zn-Cu Ferrite Stacked Films by Aerosol Deposition Method, J. Magn. Magn. Mater., 2007, 310(2), p 2549-2551

20. Y.-H. Kim, J.-W. Lee, H.-J. Kim, Y.-H. Yun, and S.-M. Nam, Silver Metallization for Microwave Device USING Aerosol Deposition, Ceram. Int., 2012, 38, p S201-S204

21. M.-Y. Cho, D.-W. Lee, I.-S. Kim, W.-H. Lee, J.-W. Yoo, P.-J. Ko, S.-M. Koo, Y.-K. Choi, and J.-M. Oh, Formation of silver films for advanced electrical properties by using aerosol deposition process, Jpn. J. Appl. Phys., 2018, 57(11S), p 11UF05

22. D.-W. Lee, O.-Y. Kwon, W.-J. Cho, J.-K. Song, and Y.-N. Kim, Characteristics and Mechanism of $\mathrm{Cu}$ Films Fabricated at Room Temperature by Aerosol Deposition, Nanoscale Res. Lett., 2016, 11, p 162

23. D.-W. Lee, M.-Y. Cho, I.-S. Kim, Y.-N. Kim, D. Lee, S.-M. Koo, C. Park, and J.-M. Oh, Experimental and Numerical Study for $\mathrm{Cu}$ Metal Coatings at Room Temperature via Powder SPRAY Process, Surf. Coat. Technol., 2018, 353, p 66-74

24. K. Sahner, M. Kaspar, and R. Moos, Assessment of the Novel Aerosol Deposition Method for Room Temperature Preparation of Metal Oxide Gas Sensor Films, Sens. Actuators B, 2009, 139(2), p 394-399

25. M. Zhao, J.C. Li, and Q. Jiang, Hall-Petch Relationship in Nanometer Size Range, J. Alloys Compd., 2003, 361(1-2), p 160164

26. J.S.C. Jang and C.C. Koch, The Hall-Petch Relationship in Nanocrystalline Iron Produced by Ball Milling, Scr. Metall. Mater., 1990, 24(8), p 1599-1604

27. J. Exner, M. Schubert, D. Hanft, J. Kita, and R. Moos, How to Treat Powders for the Room Temperature Aerosol Deposition Method to Avoid Porous, Low Strength Ceramic Films, J. Eur. Ceram. Soc., 2019, 39(2-3), p 592-600

28. J.R. Davis, Handbook of Thermal Spray Technology, ASM International, Cleveland, 2004

29. Y.Y. Zhang and J.S. Zhang, Recrystallization in the Particles Interfacial Region of the Cold-Sprayed Aluminum Coating: Strain-Induced Boundary Migration, Mater. Lett., 2011, 65(12), p 1856-1858

30. H. Assadi, H. Kreye, F. Gärtner, and T. Klassen, Cold Spraying: A Materials Perspective. Acta Mater., 2016, in press.

31. H. Assadi, F. Gärtner, T. Stoltenhoff, and H. Kreye, Bonding Mechanism in Cold Gas Spraying, Acta Mater., 2003, 51(15), p 4379-4394

32. T. Sakai, A. Belyakov, R. Kaibyshev, H. Miura, and J.J. Jonas, Dynamic and Post-Dynamic Recrystallization Under Hot, Cold and Severe Plastic Deformation Conditions, Prog. Mater Sci., 2014, 60, p 130-207

33. Y. Zou, W. Qin, E. Irissou, J.-G. Legoux, S. Yue, and J.A. Szpunar, Dynamic Recrystallization in the Particle/Particle Interfacial Region of Cold-Sprayed Nickel Coating: Electron Backscatter Diffraction Characterization, Scr. Mater., 2009, 61(9), p 899-902

34. D. Chu, H. Lashgari, Y. Jiang, M. Ferry, K. Laws, S. Xie, H. Sun, and $\mathrm{S}$. Li, Recent Progress in High $B_{\mathrm{s}}$ and Low $H_{\mathrm{c}}$ Fe-Based Nanocrystalline Alloys, Nanotechnol. Rev., 2014, 3(2), p 153-159

35. P. Zou, W. Yu, and J.A. Bain, Influence of Stress and Texture on Soft Magnetic Properties of Thin Films, IEEE Trans. Magn., 2002, 38(5), p 3501-3520

36. S. Sugimoto, T. Maeda, R. Kobayashi, J. Akedo, M. Lebedev, and K. Inomata, Magnetic Properties of Sm-Fe-N Thick Film Magnets Prepared by the Aerosol Deposition Method, IEEE Trans. Magn., 2003, 39(5), p 2986-2988

37. S. Sugimoto, J. Akedo, M. Lebedev, and K. Inomata, Magnetic Properties and Microstructures of the Aerosol-Deposited Permanent Magnet Films, J. Magn. Magn. Mater., 2004, 272-276, p E1881-E1882

38. G. Herzer, Grain Size Dependence of Coercivity and Permeability in Nanocrystalline Ferromagnets, IEEE Trans. Magn., 1990, 26(5), p 1397-1402

39. M. Lebedev, J. Akedo, A. Iwata, S. Sugimoto, and K. Inomata, NiZnCu Ferrite Thick Film with Nano Scale Crystallites Formed by the Aerosol Deposition Method, J. Am. Ceram. Soc., 2004, 87(9), p 1621-1624

40. G. Avramovic-Cingara, J. Zweck, J.D. Giallonardo, G. Palumbo, and U. Erb, Magnetic Domain Structure in Nanocrystalline Nickel Electrodeposits, J. Appl. Phys., 2018, 123(23), p 234301

Publisher's Note Springer Nature remains neutral with regard to jurisdictional claims in published maps and institutional affiliations. 